Article

\title{
From Form-Based to Performance-Based Codes
}

\author{
Dalit Shach-Pinsly * (i) and Isaac Guedi Capeluto \\ Faculty of Architecture and Town Planning, Technion-Israel Institute of Technology, Haifa 3200003, Israel; \\ arrguedi@technion.ac.il \\ * Correspondence: dalitsp@technion.ac.il
}

Received: 24 May 2020; Accepted: 10 July 2020; Published: 14 July 2020

\begin{abstract}
The performance of the built environment is an important concern affecting the quality of life and plays a critical role in every urban milieu. However, it generally disappears in the drawing plans. Current planning regulations do not always include performance requirements as part of the planning demands. Additionally, decision-makers lack the methodology and tools to demonstrate the expected performance of the built environment. Therefore, an examination of the performance of the designed area is sometimes neglected in the planning process. Current urban plans focus mainly on technical issues, counting the number of residential units, density measures, etc. The trend of progressive planning regulations, such as Form-Based Code (FBC), aims to coordinate these separated quantitative parameters into one comprehensive 3D plan where the urban form plays as a main integrator. However, these plans still lack the demand for understanding the quality and performance of the built environment through the visualization. This article addresses this gap, the lack of understanding of the performance of the built environment in urban plans and proposes the concept of Performance-Based Codes (PBC). The transition from form-based code to performance-based-design will be demonstrated through the presentation of two performance-based models, the Solar Envelope and Security Rating Index, and the possibility of integrating them into the planning process.
\end{abstract}

Keywords: performance; planning process; architectural design; built environment; urban evaluation; building assessment

\section{Introduction}

For decades, decision-makers have lacked the methodology and tools to understand the performance of the built environment while developing new demands for its performance. This lacuna is mainly related to the lack of knowledge of how to integrate performance demands or evaluation methods to the planning process. Current urban plans mainly focus on numerical and technical issues, such as counting the number of residential units, calculating density measures, and square meters of public open areas. These measurements enable the numerical dimensions of planning to be understood but not of the qualitative dimensions of the developed urban fabric. In this case, the performance is not considered because it is not always included through the general numbers. Performance has many aspects and implications. The quality and performance of a building stem from the building itself, however, the surrounding built environment also has a mutual influence on building performance and on the urban environment as a whole. Furthermore, the urban area's performance is influenced by the quality of the public open space and of the urban area's built construction.

There is a question of what is considered as an urban environment's performance and how it can be related to the planning process. Many aspects influence a built environment's performance, among them being the access to solar radiation and natural light [1], the morphology and materials of buildings [2], the security of the built environment [3], walkability [4], privacy and visibility in urban 
areas [5], etc. Currently, several models and tools already exist and new ones are being developed with which to measure separately diverse qualities in the built environment, whose results can be visualized in mapping and design plans as well as calculated with numbers and codes [6,7].

The main aspiration is to transfer these qualities/performance-measurement results into the urban-planning process and integrate them as part of the urban development. Implementing performance analysis may affect how a building's form and location will contribute to the built environment's performance and to the public open space, as well as how this data can be used as part of the planning process. It also may affect building design, buildings' locations in the space, their external influences on the urban area, and the built environment's design.

In recent years, as a result of the introduction of green regulations and increased public awareness about environmental issues, efforts have been made by architectural design teams to introduce performative considerations during design at various advanced stages, based on existing plans that did not address these aspects in advance. This is not always an easy task due to the influence of decisions that were taken in previous stages which clearly influence the performance of the proposed design (street orientation, height and distance between buildings, etc.), or mutual influence between buildings affecting their achievable performance regarding several design aspects.

\subsection{Performance of the Built Environment}

The performance of the built environment is an important concern affecting the quality of life and plays a critical role in every urban milieu. However, it generally disappears in the drawing plans, especially at the neighborhood level.

Planning regulations do not always include performance requirements as part of the general planning demands in many developed countries (for example, U.S., England and more), and concepts like carrying capacity envelope in performance-based planning have been proposed to ensure that a project conforms to an environmental performance requirement [8-10]. Moreover, these requirements are abstract, and urban forms that can be generated, based on these planning regulations which focus mainly on quantitative aspects, do not ensure environmental qualities since they are not embedded in them. Therefore, an examination of the qualities of the designed area and its performance may be neglected in the planning process $[8,11,12]$.

To date, diverse models and tools that measure various qualities of the built environment are being developed, demonstrating their results in 2D and 3D; for example, measuring the potential for using natural lighting or solar potential in buildings (in 3D), or, measuring the sense of security levels in the built environment (in 2D). However, the measurement results of these methods are not included in the planning process or demands, and are not integrated into the implementation plans and regulations.

Current planning processes are mainly based on zoning regulations [13], which lack the ability to integrate performance aspects into designs, both for buildings and the built environment as a whole. However, this planning regulation system is currently in a diverse process of change. One direction is towards the concept methodology of the form-based code-FBC [14], which will be described in detail later in this article. FBCs are aimed at shifting the initiation of the design and planning processes from two-dimensional (2D) toward three-dimensional (3D) design, generating a comprehensive 3D design process that includes all planning components [15]. This has created a paradigm shift in the planning and design process but still lacks the ability to assimilate performance into planning and design. Integrating performance information into planning design regulations will allow designers to better understand the buildings and urban fabric they design in order to achieve better urban planning.

Several obstacles are hindering performance from being integrated into planning and design processes: (1) no common methodology exists that allows various performance/quality analysis models and tools to be integrated into the planning process, and (2) no common language and criteria exist between different performance aspects and analysis models and the masterplan language system for implementing performance within the planning and design process. 
To address the abovementioned need, this works presents a novel approach where the expected or desired performance of the urban environment is embedded a priori in urban plans and proposes the concept of Performance-Based Codes (PBC), ensuring the achievement of a certain level of environmental qualities determined by planning authorities.

\subsection{Objectives}

The main objective of this article is to understand the role of performance in the planning process and how urban and building performance can be integrated into the planning and design process. The research aim is to recommend a methodology for transforming performance-measurement results into implementation plans and regulations, in reference to 2D and 3D levels of the urban environment, to improve urban design. This will be based on the conceptual design model of FBC and its development towards the next level of $\mathrm{PBC}$ for embedding performance regulations into the planning and design process.

\section{Performance Analysis Models and Tools (Literature Background)}

Methods and tools for assessing neighborhood sustainability have become widespread since the beginning of the 21st century in many communities. Carmona [16] determined that place quality is a basic necessity of urban life and has a major impact on people's lives. Carmona and Sieh [8] argued that the lack of understanding of the qualities that make up public space is the root cause of the deterioration of public space. Waldner [17] searched for evaluation methods within planning documents. Her findings showed that the word "valuation" is mentioned in general, and is mainly carried out by either (1) an "inventory checklist" or (2) retrospective evaluation during the development of a new/alternative plan; however, in neighborhood masterplan plans, no evaluation references were found.

Carmona and Sieh [8] argued that to identify the quality of planning, it is necessary to develop a working framework that breaks down the concept of quality into components based on existing analysis methods. Carmona and Sieh, and Carmona and Magalhães $[8,18]$ determined nine measurable environmental qualities, the "Positive Local Qualities" (PLQ), which summarize a wide range of environmental dimensions that are interconnected and interdependent: clean and tidy, green, unpolluted, secure, safe, accessible, socially inclusive and fulfilling, economically vital and viable, and physically attractive. This multi-quality analysis is based on a questionnaire and is used to formulate a "Community Quality Profile" (CQP), a quality assessment tool, on a community or neighborhood scale, that encompasses forms of public space connected to the local environment within a site. Later, Carmona [16] developed the "Place Quality" tool for measuring quality in public open spaces. It examines the relationship between the built environment and the value it generates in relation to health, society, economy, and environment. This means adding value to a place, and can, in turn, serve as a measure of the quality of a place; however, done in already existing places. This approach expresses the idea that quality dictates value and value defines quality, which means that the design of a place has significant influence over the quality of the environment that the place generates.

Over the years, several approaches and measurement tools have been developed to evaluate diverse aspects of the planning program and documents. Waldner, Kent, and Baer $[17,19,20]$ defined several approaches for evaluating planning documents, for example, spatial comparison (examining the plan versus the existing situation in the developed area); decision consistency/indicators (examining the planning implementation in light of permanent indicators); value-driven (selecting one single parameter that examines the plan, for example, the building growth); and holistic case study (a method for analyzing the city using in-depth analysis of case studies). Another approach is the cost-benefit analysis (CBA)/investment analysis, an approach that connects the monetary value to the production of a project, which is the most profitable model among U.S. planners [21].

Talen [22] pointed out that the "Impact Assessment approach," which involves an extensive examination of the planning program and its implications, sometimes is used in light of a particular 
dimension. For example, Kent and Baer $[19,20]$ suggested a typology of a masterplan functionality system that dictates the object for assessment (e.g., planning instructions, plans, planning appendices, etc.). However, Waldner, Kent, and Baer $[17,19,20]$ pointed out that "invisible evaluation"-invisible assessment in which the planners may evaluate their plans, but not scientifically, publicly, and systematically, which is not accessible to the public and to research-is one of the most common approaches for evaluating planning.

Currently, many evaluation tools are mainly used to measure the sustainable development goals' success of diverse buildings and neighborhoods [23]. The results of a study that comparatively examined seven sustainable evaluation methods and tools indicated that several aspects are either neglected or under-evaluated, such as the coverage of social, economic, and institutional aspects of sustainability [23].

The concept of sustainable planning and development aims at developing new requirements for urban areas which include conceptual principles and practices for land use and urban planning for creating sustainable communities [24]. This includes diverse aspects of development such as the physical, economic, social and environmental aspects, renewable energy, ecology, clean air and water, land use and more [25-27], and involves many disciplines, including environmental science, economic development, architecture and engineering, transportation and more [28]. Over the years, this concept became increasingly indispensable for decision-making in many countries around the world [29]. This concept involves practical approaches, models and tools for evaluating urban planning [24] including, for example, sustainable solutions for urban mobility [30], geospatial approach for urban growth [31], carrying capacity assessment [32], alternative energy sources such as solar and wind [33], green buildings and housing [34], mixed-use developments [28] and more.

There are several widely used sustainability assessment tools in many countries around the world for evaluating urban planning and development [29]. For the last few decades, green, sustainable evaluation tools have been developed around the world, such as LEED, BREEAM, Green Star Community or SI 5281 in Israel. LEED (Leadership in Energy and Environmental Design) was developed by the U.S. Green Building Council (USGBC) and is accepted nationally as a basis for green building practices $[29,35,36]$. LEED includes a set of rating systems for design, construction, operation, and maintenance for using resources efficiently [37]. The LEED-ND for neighborhoods is a rating system that integrates principles of urbanism, smart growth, and green building into a U.S. national system for neighborhood design. It recognizes urban projects that enhance overall health, natural environment, and quality of life parameters integrated into the projects by promoting neighborhoods that reduce vehicle miles traveled, accessibility for services and job opportunities, public transport, green building and infrastructure, and natural areas [38].

The BREEAM (Building Research Establishment Environmental Assessment Method) is a method for assessing, rating and certifying buildings' sustainability based on sustainable metrics and indices that cover a range of environmental issues such as health and well-being, waste, ecology, management processes, and more. The BREEAM was established by the U.K. Building Research Establishment (BRE) and later was adopted by the U.K. government as a system to measure best practices of environmental design and management [36,39]. Currently, this system is used in more than 50 countries worldwide. The BREEAM also has a tool that focuses on neighborhood development [23,29].

In Israel, a Green Buildings Standard, SI 5281—buildings with reduced environmental impact (green buildings)—was developed and approved some years ago [40,41]. The standard is a set of criteria and requirements for examining new and thoroughly renovated buildings, by scoring points and compliance thresholds. Besides being a means to implement environmentally friendly construction targets, SI 5281 can be seen, along with similar standards and rating systems around the world, as a comparative tool for the analysis and ranking of the performance of buildings in various environmental areas. 
Israeli Standard SI 5281, in its first version [40], "Buildings with reduced environmental impact (Green Buildings)", was approved in November 2005 by the Technical Committee on environmentally friendly buildings of the Standards Institution of Israel.

The first version of the Green Standard was lately updated with SI 5281 "Sustainable building (Green Building)" [41] to provide a clearer and uniform criteria for assessment, a more detailed scale for classification of buildings (five levels from one to five green stars) and includes additional building types besides residential and office buildings. The various sections of the updated standard also reflect ideological changes relative to its first version. Some of the changes reflect a new way of interpretation of certain properties that also exist in the first standard; others are reflected in the updated criteria, thus adding some new features and requirements [42].

The Green Star Community is a sustainability rating system for buildings in Australia that was established in 2003 [36]. The Star Community ratings can be achieved during the planning phases of the design, building construction, or the development phase. The rating system also considers residents' health, productivity, and operational cost savings.

The neighborhood $-360^{\circ}$ rating system that was recently developed in Israel is a measurement tool that aims to promote the design, development, and construction of quality, healthy, livable, and prosperous neighborhoods. The system consists of three main sections: infrastructure and construction, natural and public space, and efficient use of resources. Compliance with the requirements allows for the accumulation of score points for the entire project. These requirements enable the implementation of quality principles in various design stages. The system incorporates multi-dimensional development challenges by setting assessment and benchmarking criteria for the quality of the planning process [43].

Additional tools were developed for evaluating city resilience. The City Resilience Index $[44,45]$ tool was developed to assess cities to measure and monitor diverse factors that contribute to city resilience. The index relates to four key dimensions: health and well-being, ensuring the health and well-being of people; economy and society, enabling urban populations to live peacefully and act collectively; infrastructure and environment, providing critical services, protecting, and connecting urban citizens; and leadership and strategy. The index is based on quantitative and qualitative questionnaires over diverse topics for the assessment. Another method is the CART-resilience toolkit that includes a resilience survey as well as additional assessment and analytical instruments to improve community resilience issues [46].

The methods mentioned above are mainly rating-based methods, not planning-based methods. These measurement tools provide an overall score for the planning documents and program, such as "outstanding, excellent, very good, poor and good" (BREEAM), "Platinum, Gold, Silver and Certified" (LEED) or A+, A, B, C, D (SI 5281), and the analysis is done on a large scale and does not go into the planning and program details. The overall score is characterized by categories so that the degree of the overall quality of the plan can be understood, and lacks the spatial/visual analysis of the quality of the environment. Therefore, the above methods are fundamentally different from the method proposed in this paper, which attempts to evaluate the performance of the planning and design through spatial performance analysis of the quality of the buildings and the area/neighborhood environment that can be seen.

\section{The Planning and Design Process}

In this work, we refer to the planning and design process as a comprehensive and continuum course of action which starts with the definition of the requirements program for a new urban site and ends with the development and construction of new buildings and open areas. This process involves actors from different disciplines: decision-makers, urban planners, architects, and designers who work independently in their respective fields. However, the design possibilities and potential of the final design will be influenced by decisions taken in previous stages of the overall process, as shown in Figure 1. Therefore, if we aim to achieve a good environmental performance of each one of the 
components (buildings, public/private open areas, etc.) we need to make sure that these aspects are considered very early in the planning and design process.

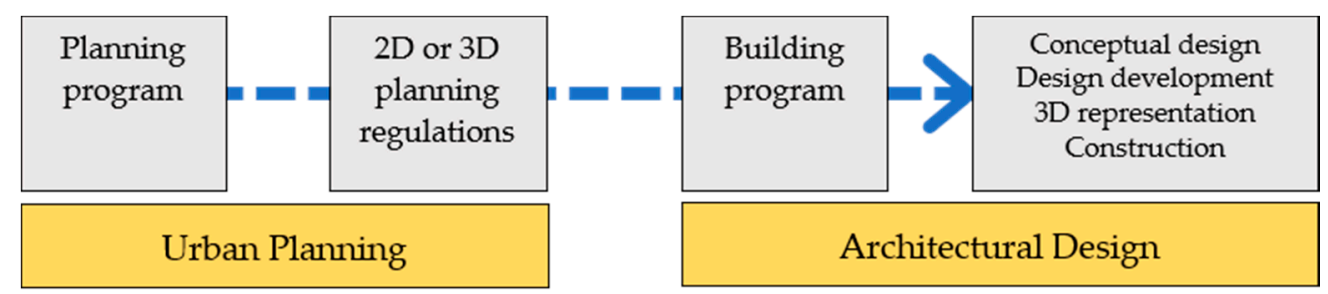

Figure 1. The planning and design process.

Planning processes are mainly based on zoning regulations in many countries [10,13], which leads to a certain way of developing an urban area [47]. Zoning is a regulation system of land use planning used by local or national governments in many developed countries as a tool for developing urban planning to guide urban growth and development. The system divides land in a municipality into zones based on usage (residential, commercial, industrial, etc.). The zone type determines the area regulations and the types of buildings, planning permitted for development, as well as the regulations specifying a variety of conditions for land uses, including the sizes of the area lots and the form of buildings [8]. Most of the planning is based on 2D plans accompanied by verbal planning regulations and some 3D demonstrations. Current planning regulations are mainly related to separately "counting" different quantitative parameters, most of them uncoordinated. Yet, the zoning-regulation system does not include performance-regulation parameters [8,11].

The last decades challenged urban design toward developing new innovative approaches, focusing on technology for analyzing and evaluating diverse aspects affecting urban design [48-50], arguing that the urban design process can be more effective by using such analytical methods [51]. These methods can evaluate the design outcomes objectively and assist in the development of design solutions [51], for example, The Citizen Design Science tool for integrating citizens' ideas into the urban planning process [49] and analytical models of space syntax [51]. In addition, building design is also challenged by using analytical methods for developing better effective buildings, for example, the NewFacades model is a significant concept that assists in assimilating intelligent façades in the design [52], the model for multiple-criteria decision-making for building design [53], or the computational optimization models applied for solving sustainable building design problems [54,55]. In addition, there are tools used for evaluating urban open spaces such as the Spaceshaper [56] that provides a toolbox for evaluating the functionality of a given public space before investing time and money in improving it, or the "public space index" [57] for evaluating the quality of public spaces. However, these processes of evaluation still are not integrated into the planning and design process $[11,12,58]$. These evaluation models need to be adopted into the planning and design process following the planning, urban design, and the building design development phases serving as the evaluation phase of the design process.

Performance-based planning was suggested as an alternative to conventional prescriptive zoning for land use regulation. Performance zoning permits a wide variety of land uses as long as each land use is able to meet the required performance standards, according to needs and concerns of the local community. Performance zoning provides flexibility in the development of property and guarantees protection of neighboring and nearby properties [59]. However, there has been little empirical attempt to measure the concrete impacts of performance-based decision-making on real planning outcomes, and most are based on qualitative assessments of expert opinion about impacts, rather than the impacts themselves $[9,10]$.

For the last decade, there has been awareness about the need for a shift in regulations and plans, for a better understanding of the resulting built urban sites. The trends in current planning regulations are to coordinate separate quantitative parameters into one coherent 3D plan that visualizes the built environment as one comprehensive environment. The urban form acts as the main integrator, as can 
be seen in the newly developed mechanism of the Form-Based Code (FBC), which visualizes the built environment as one comprehensive result. However, the performance aspects of the designed built environment are not included in these new regulation systems and drawing of plans.

The Form-Based Code (FBC) is a new approach and an alternative to conventional zoning regulations. At its base is the idea of a neighborhood or city as a whole, rather than its division by specific land uses. The FBC promotes regulation that fosters the 3D built-up environment by using the urban form as the organizer principle instead of using distinctions in land use types [15]. Form-Based Code promotes the visual approach to masterplans and drawing plans, provided by a legally binding map, differing from the zoning and masterplan approaches of the previous decades. It relates to urban block types, the relation between building forms and volume in relation to one another, building façades and the public open space, street types, and scale. It contains a number of important components: regulating plans, public space standards, building form standards, administration, and glossary. Each component serves to elaborate on the other in order to give a complete visual and verbally-defined picture of the legally binding code [60]. The code referred to walkable, human-scaled neighborhoods, focusing on urban form but also accounting for the use and other factors. The new approach to masterplans was then very different than the approaches that preceded it.

The Regulating Plan is presented as a map with codes and standards marked at certain locations. This map places the regulations laid out by the FBC on the physical layout of the planned area, with elaborations of these markings in the following sections. Unlike zoning ordinances, that control plans through uncoordinated parameters (e.g., counting dwelling units, density measures as dwellings per square meter, housing borderline, setbacks, parking ratios), and neglects the integrated built form. The FBC marking is not defined by land use but rather by type, designating certain spaces "Main Street" or "Sub-Urban," rather than "Commercial" or "Residential." [61].

"Public Space Standards" and "Building Form Standards" lay out the public realm in detail. "Public Space Standards" refer to thoroughfares specifying pedestrian, bike, automotive, and transit routes as well as regulating civic spaces. "Building Form Standards" elaborate on the required components of individual buildings. The structures are assigned specific lot sizes, placement within the planned area, as well as being detailed by their use and "frontage," or façade. In order to ensure proper implementation, the Administration section delineates the application and review of the previous units. Furthermore, whatever was not made clear in the Standards elaborations is defined in the glossary, therefore, the FBC then becomes a comprehensive document [62]. An important factor in the development of FBCs is the element of public participation, a collaborative process in which all stakeholders take part in visualizing a vision for their community. This method of disclosure through visual aids not only allows public participation but also encourages it, as the proposals are made highly accessible [60].

Although the FBC framework enables a better understanding of the built environment, organizing the urban form's principles and morphological characteristics into a more coherent perspective of the urban area, the performance aspects of the designed built environment are not included in these new regulation systems. On the other hand, there are different methods for evaluating and measuring various aspects of environmental quality that affect the built environment's performance. The possibility of integrating these methods results in the planning process will greatly affect the urban area's performance.

There are difficulties that prevent the process of integrating performance requirements in advance and may raise obstacles, such as the design/analysis language, scale differences, additional urban analysis layers, determining how to integrate the evaluation into the planning process, integrating analysis data into the planning regulations, and coherent $2 \mathrm{D}$ and $3 \mathrm{D}$ analysis. For this reason, we propose a continuing process-a Performance-Based Code (PBC)-aimed at integrating the performance/quality analysis into the planning and design process, which will include the performance requirements and results for the buildings and urban area. 
Figure 2 presents the planning process and its relationships with performance results for the built environment in 2D and 3D: (a) the influence of the zoning-based system; (b) transformation to FBC; and (c) the proposed possibility of embedding in $\mathrm{PBC}$ the performance requirements and analysis into the planning and design process. The following sections will demonstrate the possibility of integrating PBD into the planning by using two available methods.

\section{Zoning-Based-Code}

Quantitative
requirements
Numbers of units
Density
Urban usage

Unknown Form

Form-Based-Code

Quantitative
requirements
Numbers of units
Density
Urban usage

Unknown Form

\section{Performance-Based-Code}

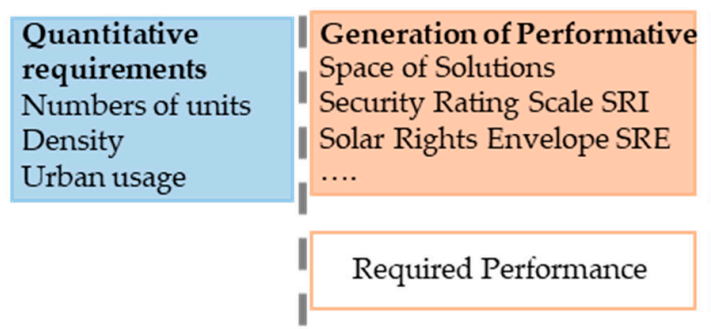

Assisting 3D drawings
(Building and street
layout, landscape, .....)

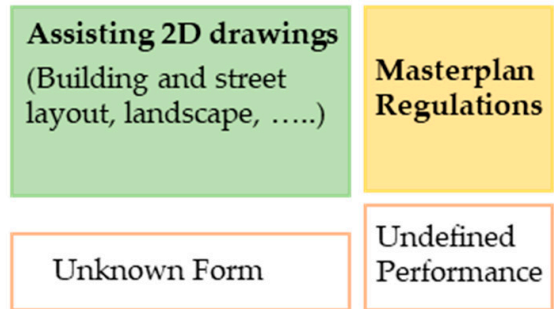

Masterplan

Regulations

Undefined

Performance

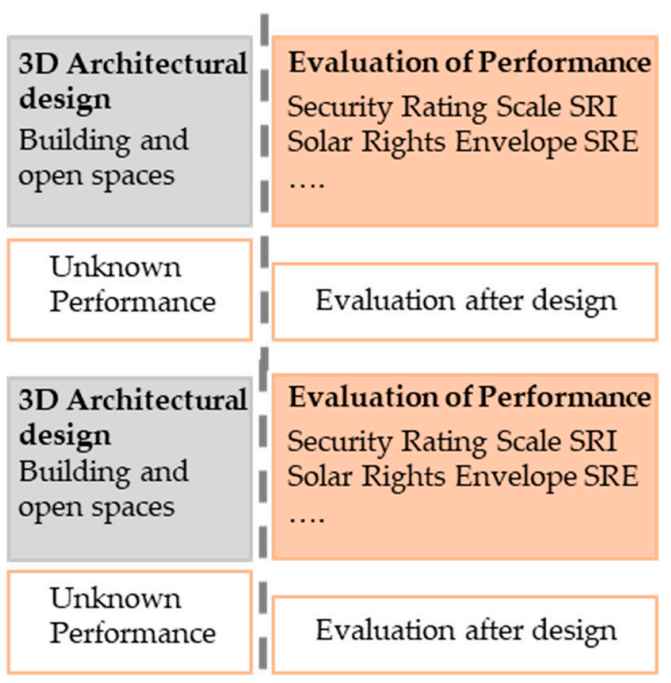

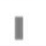

\begin{tabular}{|c|l|l|}
\hline $\begin{array}{l}\text { Assisting Performative } \\
\text { 3D drawings } \\
\text { (Building and street } \\
\text { layout, landscape, ....) }\end{array}$ & $\begin{array}{l}\text { Masterplan } \\
\text { Regulations }\end{array}$ & $\begin{array}{l}\text { 3D Architectural } \\
\text { design } \\
\text { Building and } \\
\text { open spaces }\end{array}$ \\
\hline Known Form & $\begin{array}{l}\text { Pre-Defined } \\
\text { Performance }\end{array}$ & $\begin{array}{l}\text { Known } \\
\text { Performance }\end{array}$ \\
\hline
\end{tabular}

Figure 2. Demonstration of the planning process and its relationships with performance requirements and results.

\section{Performance-Based Planning Design}

In planning aspects, performance-based planning can be understood as an evaluation approach to the urban planning process for measurable or predictable performance in terms of diverse qualitative aspects of the built environment. The ability to include diverse qualitative aspects of an urban area (such as safety, security, comfort and walkability) during the planning process assists planners by adding different measurable layers to the design and may allow a better understanding of the developed urban environment's nature.

Urban morphology has essential effects on how people utilize as well as feel and behave in urban areas, where a particular urban morphology can create a walkable or unwalkable urban space. An area's urban morphology contributes to certain feelings and behaviors in an urban situation, such as the sense of feeling secure or insecure [3], or being willing to walk through or stay in certain urban areas [63,64], or having visibility sightlines from different locations in the urban area [5]. Therefore, the quality of the urban morphology, developed and created through the urban planning process, influences the feasibility of better performance of an urban area and may lead to a more livable built environment.

Qualitative urban data can be generated from evaluation models and can affect performance. Ewing and Clemente [65] developed a method based on urban data for measuring qualities of a street's urban design and associating it with walkability. Other researchers have studied physical activity and walkability in relation to health, resulting in data that can be assimilated into the planning 
process [66,67]. Shach-Pinsly [3] developed the Security Rating Index (SRI) to measure and rate insecure urban spaces based on urban elements which can also be embedded in the planning process.

As can be seen, evaluation models can produce data to contribute to an urban fabric's performance requirements and assist in developing place-tailored urban morphology. Assessing the built-up environment early into the planning process may significantly affect a place's performance and influence its character-whether it will be a livable or a deteriorated urban area. Data information and its transparency play a critical role in an urban area's performance, and more transparent data will make the data better embedded into the planning process and result in a better understanding of the urban area's performance. As a whole, early decisions in the wide-scale planning process affect an urban environment's performance and people's behavior as well as influence the performance of buildings in an urban layout.

In architecture, performance-based design can be understood as an approach to design a building which meets measurable or predictable performance requirements regarding certain aspects. Performance-based design recognizes that different forms can successfully achieve similar functions, and that different functions can often be afforded by similar forms [68]. Furthermore, performance criteria can contradict one another. This forces the designer to rank (using formal or calculated criteria) each performance within a hierarchy of influence. By not fully adhering to any criteria, the design solution stops being optimal and becomes subjective, which aligns it with traditional design [69]. This approach is based on the existence of a space of solutions that comply with performance requirements, and therefore maintains the freedom of the designer in determining the final form.

Performance-driven form-generation refers to the idea that performance data can be used to generate architectural form. Generation tools [6] may aid to define the proper geometry to achieve a certain performance. For example, the geometry of the urban grid affects the wind conditions and shading zones created in buildings and open areas. Consequently, it determines whether those places will be thermally pleasant or uncomfortable during different hours of the day and throughout the year. Streets and other public open spaces that allow solar exposure during winter, and shading during the hot-season, provide the proper conditions to sustain urban life [70]. Shaviv [71] proposed a method and a computerized model for the design of fixed external sunshades. The method was extended later for the generation of solar rights envelope for the design of solar communities [72]. Arumi [73] developed a computerized model that determines the maximum allowed height of a building that does not violate the solar rights of the existing neighboring buildings. Knowles [74] suggested a method for assuring solar access to each residential unit in a community.

Hence, early decisions in the wide-scale planning process affect an urban environment's performance and people's behavior as well as affect the performance of buildings in the urban grid. For this reason, performance-based planning design can be also considered at the urban scale and embedded in planning regulations through Performance-Based Codes.

\section{From Form-Based Code to Performance-Based Code}

The trend of progressive planning regulations, such as Form-Based Code (FBC), aims to coordinate separated quantitative parameters into one coherent $3 \mathrm{D}$ plan, visualizing the built environment as one comprehensive environment where the urban form plays as a main integrator. However, these plans still lack the demand of understanding the quality and performance of the built environment through regulation and visualization. Although there are several models and tools for evaluating and measuring different aspects of the qualities and performance of buildings and urban environments, as demonstrated by visualization, drawing, and calculation codes, the design and planning process still lacks these performance outcomes as a part of plans and regulations. The matter of integrating these results into the design and planning process remains unsolved.

For improving progressive planning regulations towards performance demands, several obstacles arise for this process, such as: how these performance-measurement results can be facilitated through the design plans; what will be the process for integrating the performance results into $2 \mathrm{D}$ and $3 \mathrm{D}$ 
design plans using a common planning and design language; how the performance results should be demonstrated in relation to the general design and planning analysis (e.g., density analysis, housing units, open spaces, land use, functionality, etc.); and how the performance results can be examined objectively during the planning and design process.

To overcome these obstacles, a comprehensive methodology suitable to the planning process is needed that will allow the evolution from FBC to PBC for integrating performance into planning and design language. Furthermore, the performance-outcome results must be transferred into planning-code and visualizations that fit existing tools, as a basis for designing performance regulations for the planning process. The developed PBC process will be demonstrated through the use of two models: the Security Rating Index (SRI), for analyzing the sense of security in the built environment and the Solar Rights Envelope, to ensure the desired solar access on open spaces and at building surfaces. The selection and weighting of the design criteria are critical for the evaluation process and must reflect the concerns, values, and needs of the local community; dealing with this subject requires additional elaboration which is out of the scope of this paper.

\section{Demonstration of Planning and Design Analysis Model}

\subsection{Security Rating Index (SRI)}

The sense of being secure in an urban area influences how people act and behave and is valuable information that needs to be integrated into the planning process and plans. This sense can be measured using the Security Rating Index [3], which establishes a framework for a security rating scale in urban environments for assessing and improving urban resilience. The index is based on measurements of urban parameters (mixed uses, building proximity, streetlights, and intersections) related to security by employing urban morphologic analysis, and can identify characteristics and hot spots of vulnerability within a city.

The outcomes of the SRI analysis are daytime and nighttime security maps of the built environment. The security analysis can point out specific urban characteristics that unveil unsecured locations in the daytime and nighttime, such as secure or insecure public open spaces, gardens, or paths in the drawing plans. The SRI model assists with explaining urban functionality and why certain urban areas tend to be more insecure than others. The results of this analysis may suggest urban changes and adjustments to improve the unsecured areas, such as urban usage changes, suggestions for secured walking routes during the day and night, monitoring of neighborhood security measures, neighborhood connectivity improvements, and the development of a basic urban decision-making process for potential renewal of improved secured areas in the built environment. Applying the SRI can aid designers with improving the security levels of existing and new urban areas along with including security considerations into the urban decision-making process. This valuable information can be integrated into the planning process for the benefit of the designers and decision-makers.

A comprehensive literature survey of urban elements was conducted to develop the model. The urban element survey identified 35 urban elements influencing the sense of security. Additional investigation determined four main urban elements for measuring the sense of security: mixed uses, building proximity, streetlights, and intersections (distances between junctions and the number of intersections). Each received a tailored weighted scale following the literature review. For mixed uses, a higher number of uses in an urban area raises the level of security; for building proximity, the lower the distance between buildings, the higher the level of security [5,64]; for streetlights, the higher number and density of streetlights increase the level of security; and for number of intersections and distance between junctions, the higher the number of intersections and the greater the distances between intersections in an urban area, the greater the level of security [3].

The weighted scales were defined according to the statistical investigation for each selected urban element. The scale for measuring the sense of security was weighted between 1 (low sense of security in the built environment) and 5 (high sense of security in the built environment). For mixed uses, 
the highest number of uses per $25 \mathrm{~m}^{2}$ unit was five usages, and the lowest was one usage. For street lights, a hotspot of five adjacent streetlights per $25 \mathrm{~m}^{2}$ unit will have higher security than a hotspot of five streetlights with a wider distance between them per the same area. Building proximity is based on the distance between buildings, following previous studies that measured diverse qualities in relation to distance between buildings $[5,64]$, which were adopted and tailored to $5 \mathrm{~m}^{2}$ units. For intersections, the most intersections per $25 \mathrm{~m}^{2}$ area were seven, and the least was one.

For the analysis, each variable was analyzed with suitable GIS-based selected analysis tools following their rated range. The urban element scales for the SRI were demonstrated by Shach-Pinsly [3]. The GIS tools that were used included Kernel Density, Focal Statistics, Euclidean Distance, Raster Calculator, Collected Events, and Shape to Raster. For each urban variable, a separate GIS layer was created and analyzed in a separate raster map. For integration, all of the separate raster maps were combined into one weighted-layer raster map, with each pixel summarizing all five layers, to describe the sense of security in the built environment in every area of the city during both daytime and nighttime.

To demonstrate the model, the SRI was implemented in the Hadar neighborhood in Haifa, Israel, for daytime security (Figure 3a). The analysis showed several hotspots of unsecured areas, colored red, and the areas colored green were better secured urban areas. To verify the SRI results, we used an analysis map of 106 emergency calls for vandalism and street crime in Hadar (Figure 3b). Figure 3 shows both maps, focusing on similar hotspots of unsecured areas in both maps. The model shows that during daytime, the main large sites of unsecured areas are located at the northern area of Hadar (Figure 3(1)). This area is adjacent to the Lower City neighborhood of Haifa, which is relatively deteriorated and where crime in open public areas may occur more often. There are additional unsecured hotspot locations with relatively low levels of security, such as Hadar/Technion Garden and the Balfour Street area at the center of Hadar (Figure 3(2)), which is an open garden located near the main unsecured area of the neighborhood. The Leon-Blum Hill area (Figure 3(5)) is an isolated public open space located relatively distant from residents. The triangle area between Arlozorov, Hapoel, and Bezalel Streets (Figure 3(4)) and the urban area between Yalag and Herzel Streets (Figure 3(3)) show unsecured levels on both maps, but further research needs to be done to understand the causes. The analysis showed several hotspots of unsecured areas, colored red, and the areas colored green were better secured urban areas. The outcome of the model can be accommodated as one of the planning layers presenting the security plan of the design. This layer can be used during the planning and design process by identifying hotspots of unsecured areas that need to be redesigned. At a masterplan level, the security layer can demonstrate the security level of the designed area.

To provide planners with a platform for evaluating sense of security during the planning process, the first goal will be to transfer the SRI outcomes to the planning and design language so they can be integrated as part of the planning process. As was demonstrated, the outcome was one visual weighted-layer raster map supported by numeric calculations of SRI grades (Figures 3 and 4). One solution can relate to the possibility of transforming the raster map into one layer of the design and of producing a "security plan" as part of the planning system for design plans (similar to a landscape map, building layout map, etc.). An additional solution can be to transform the calculation results into "security measurement code" results that can support and be added to the FBC. Both solutions are needed to create security regulation codes for the urban environment that can be integrated into the planning process and displayed in drawing plans. Currently, the SRI model is not integrated as part of the planning process, however, the aim is to use this model for processing the "security layer" and use it as part of the design process and outcomes. 

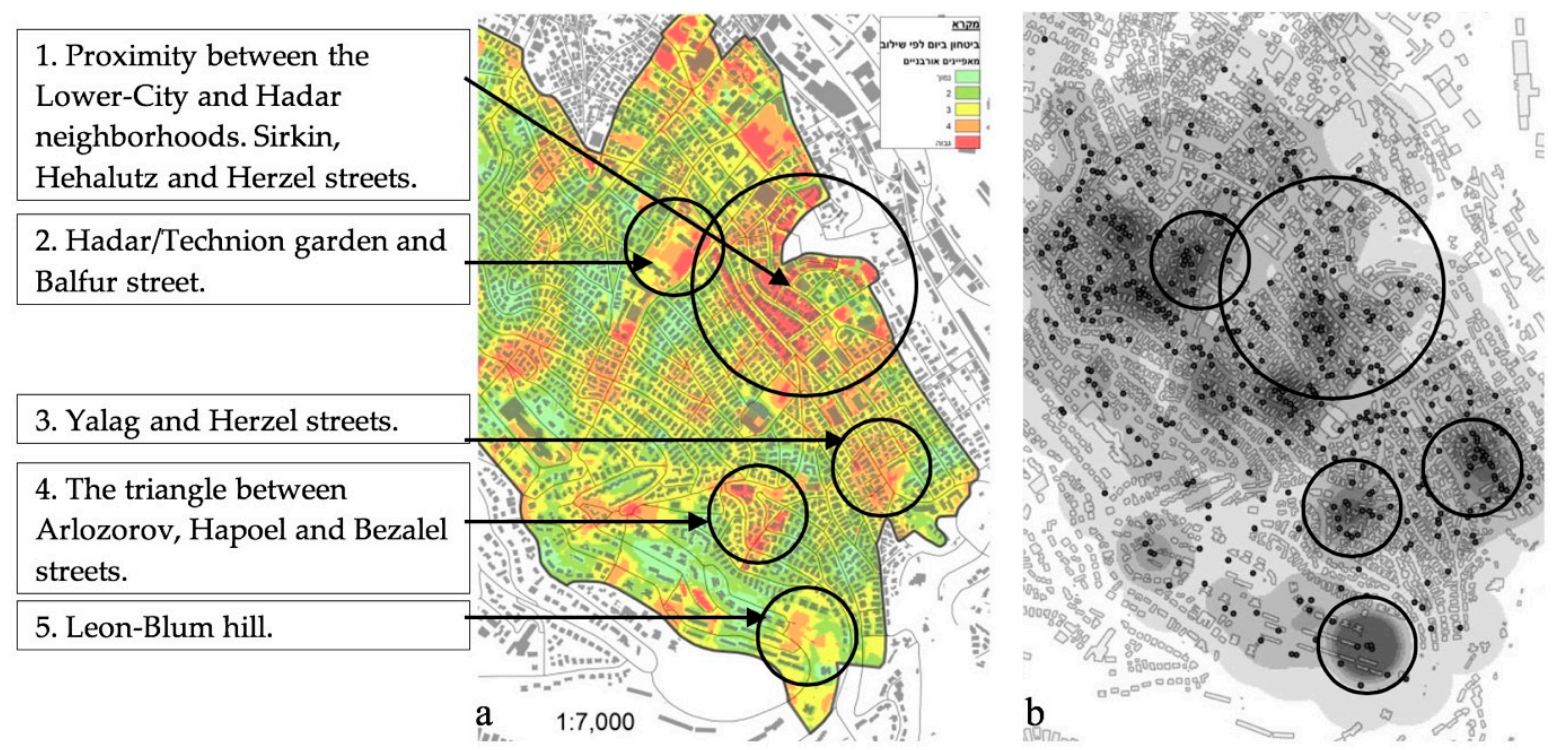

Figure 3. Security Rating Index (SRI) analysis implemented on Hadar neighborhood (a). An analysis map of 106 emergency calls for vandalism and street crime in Hadar (b).
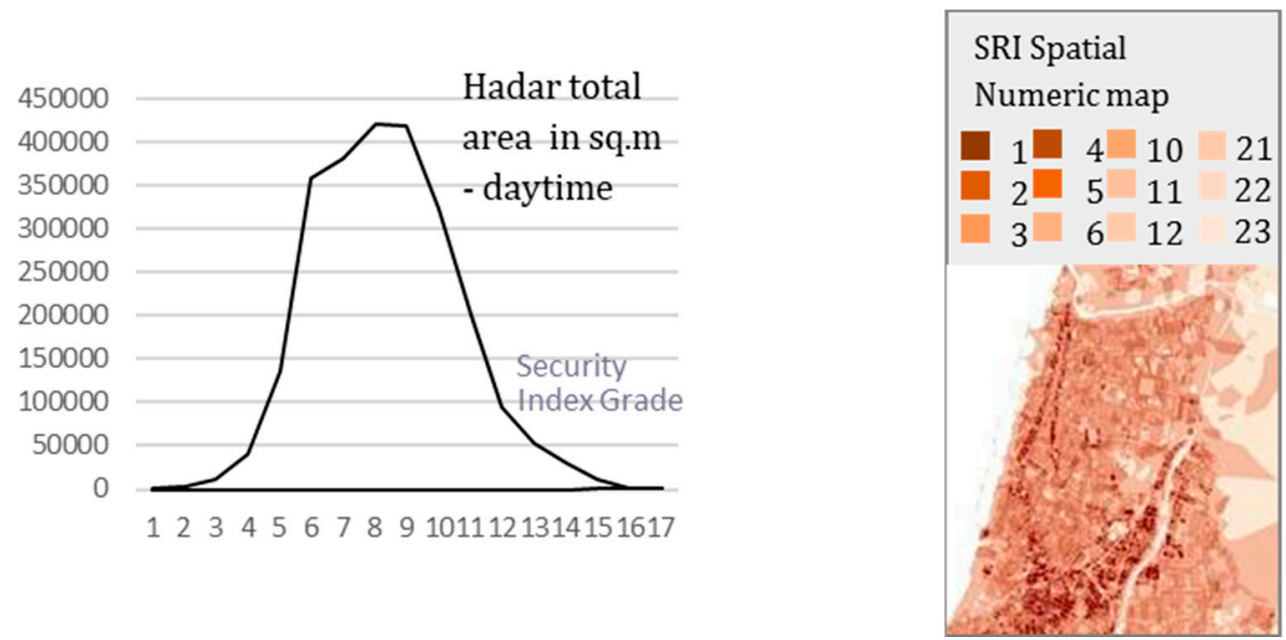

Figure 4. Hadar's total security index grade area in square meters for daytime security.

\subsection{Solar Rights Envelope (SRE)}

Considering solar access and solar rights in urban design is essential to improving comfort conditions of people on streets, sidewalks, and in open urban spaces. Moreover, passive heating of buildings in winter and maximum exposure of solar systems during the whole year must also be guaranteed in order to improve performance. A design that considers these factors may reduce the energy consumption of buildings and increase energy generation, while insolation of exterior spaces may create climatically comfortable areas that can be used for outside activities in winter. On the other hand, shading should be considered to avoid overheating of buildings and to create pleasant spaces during summer.

Planning, in such a way as to allow for sun access by regulating the form, height, orientation and organization of the built environment, has been exercised since ancient Greece and Rome. Socrates promoted solar design of houses, considering the orientation of main façades and solar exposure. Both the city and the single building design took local climate into account to achieve comfort conditions passively and allow for sun access to the built environment and open spaces. However, in modern 
times, and with cities increasing in population and built density, sun access considerations have often been overlooked in the design process, at least in part due to a lack of urban zoning regulations at an urban scale, and the relative simplicity of using electric lighting and HVAC systems at a building scale, compared to the complexity of introducing solar access considerations in the design process.

Nevertheless, nowadays, many cities in the world have defined regulations to keep solar rights. Some were created from a public point of view to keep open spaces and sidewalks insolated, as defined in cities such as New York, San Francisco, Toronto, and Tel Aviv. In other places, regulations were defined to ensure the full use of private properties such as private open spaces and solar collectors. The cities also differ in their approach for application of the regulations and demonstration of compliance with them.

\subsubsection{Solar Envelopes}

The concept of solar envelope has been proposed by Knowles [74] as "a way to assure urban solar access for both energy and life quality" [75]. Capeluto and Shaviv [76] further developed the solar envelope concept suggesting the creation of two different types of solar envelopes: Solar Rights Envelope (SRE) and Solar Collection Envelope (SCE). These envelopes define the space of solutions for the determination of a design that considers, in advance, either insolation or solar shading: The SRE presents the maximum buildings' heights that assure the solar rights of any existing building or selected open area, during a given period of the year. The SCE, on the other side, presents the lowest possible location of windows and passive solar systems, so that they are not shaded by the existing neighboring buildings during a given period of the year. Clearly, it is also possible to determine the volume contained between both envelopes, which allows solar access to all the surrounding buildings, and at the same time, are not shaded by them, referred to as the solar volume (SV) (Figure 5).

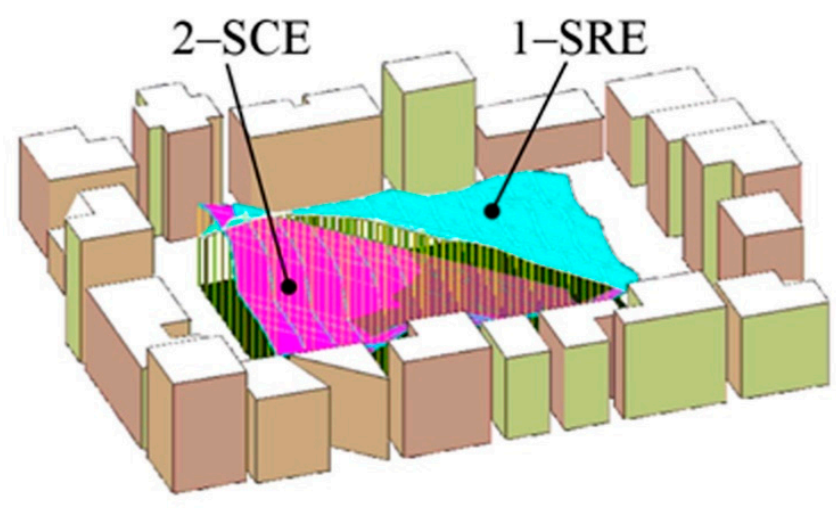

Figure 5. Solar Rights Envelope (SRE) (1), Solar Collection Envelope (SCE) (2), and solar volume (SV).

This idea was further developed by Capeluto and Plotnikov [77] by introducing the concept of context-dependent parametric solar envelopes to maximize the potential built volume in dense urban environments. By differentiating between different conditions and exposure requirements in a mixed-use environment, it is possible to refine the criteria for the creation of the envelope according to programmatic requirements, creating solar envelopes which are truly site-specific and take the local climate and the built context into account.

\subsubsection{Solar Rights in Urban Design}

In existing built areas of cities, designers and planning authorities have the opportunity of using solar envelopes as a means to transform and define their future development, taking into account solar access considerations without compromising design freedom. Solar envelopes were adopted by the planning authorities of the municipality of Tel Aviv for the development of a 250,000 $\mathrm{m}^{2}$ business district, considering solar rights of buildings and green open areas (Figure 6, left) [78]. 
More recently, the architecture and urban design practice MVRDV proposed a competition-winning masterplan to renovate and redesign old historic structures in a $350,000 \mathrm{~m}^{2}$ area near the center of Bordeaux [79]. They proposed to commission the architectural design to 144 different offices to achieve a rich architectural variety, on the basis of the solar envelopes for each plot (Figure 6 right).

a
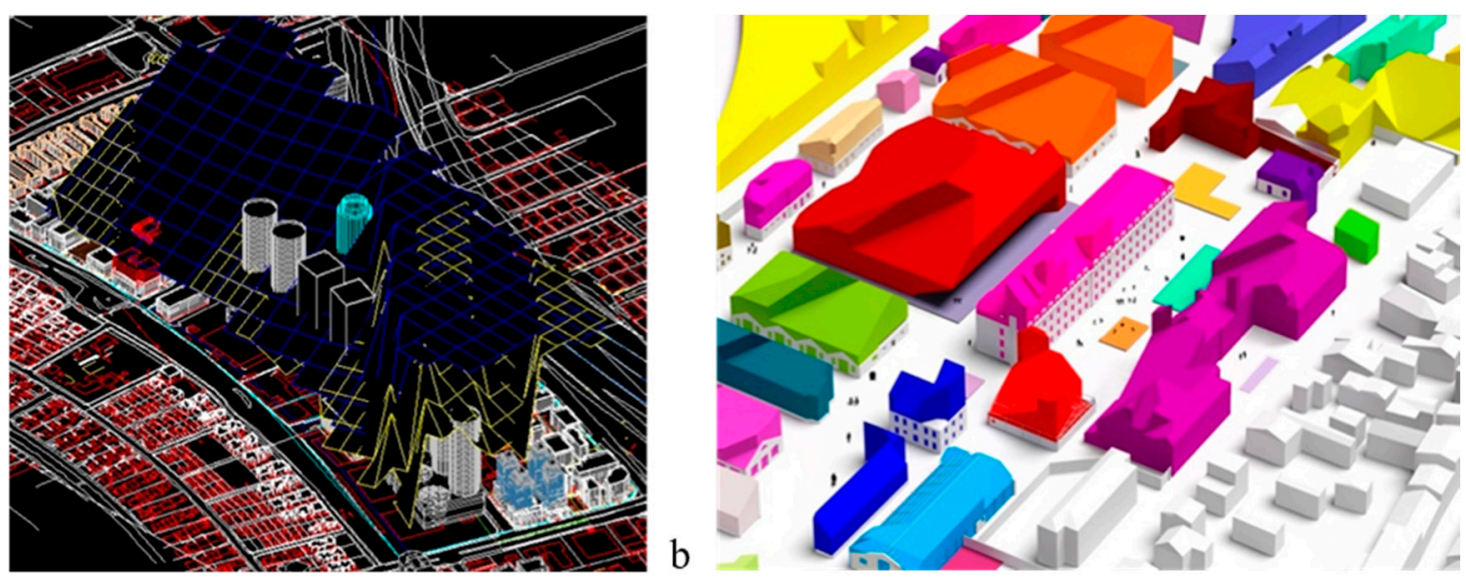

Figure 6. Solar Rights Envelope in a business district in Tel Aviv (a) and Solar Envelopes in MVRDV's Bastide-Niel master project in Bordeaux (b).

The idea of solar envelopes can be also implemented in a new unbuilt area at the stage of the plan preparation. For this purpose, we can define streets and lines on the ground that border each subdivision, and set the solar access requirements on each plot according to its future use as well as generate the solar envelopes. The resulting SRE (which, in this case, is also the SV), defines the 3D space of solutions that comply with the solar rights performance requirements in advance, in such a way that the shading of neighboring buildings, solar systems and surrounding open areas are predetermined according to planning performance requirements. In this way, every architectural solution generated using the envelope as a guideline provides the environmental quality required by the plan regarding this specific aspect (Figure 7).

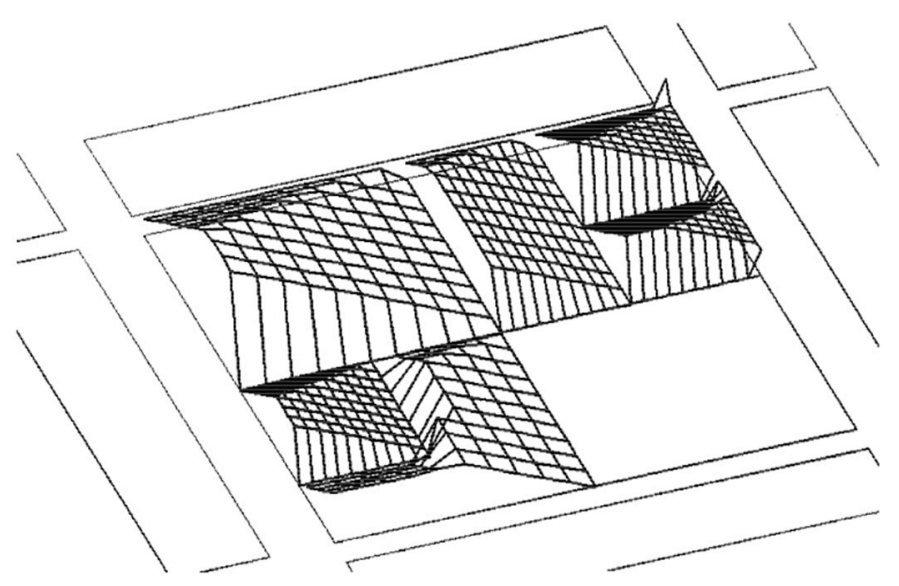

Figure 7. Solar Rights Envelope embedded in advance in a new plan.

\section{Results and Discussion}

The analysis results of the two methods produced different outcomes. Each of the outcomes is expressed by different parameters. Therefore, the main question relating to the planning process refers to the need to generate a process that will produce several alternatives for different environmental aspects. 
Figures 8-10 demonstrate an alternative approach, referring to these needs through the demonstration of outcomes of the SRI and SRE results along with their assimilation in the planning process.

Figure 8 demonstrates a process for transferring the SRI outcomes toward a general planning evaluation layer. The SRI outcomes are expressed as a weighted-layer raster map supported by numeric calculations that can be transformed into one layer of the design. An alternative outcome to the raster map is a key-legend-code map of the urban security level of the designed area. Both outcomes can generate a layer of the "security regulation code" as an appendix to the masterplan program plans.

Figure 9 demonstrates a process for transferring the SRE outcomes toward a general planning layer. The SRE presents the context-dependent parametric solar envelopes in 3D-2D vector lines and volume. These measurements define the criteria for the solar envelope parameters as programmatic requirements. These outcomes can also be translated into a raster map, presenting the maximum building heights that assure the solar rights of buildings/open areas, for several periods of a year, which leads to the creation of a spatial code map that can be attributed as a planning appendix to the masterplan program plans, as demonstrated in Section 5.2.1.

Hence, as mentioned earlier, generating a comprehensive performance evaluation of different environment qualities and assimilating it into the planning process, along with integrating both architectural and planning perspectives, is the main challenge. This requires a new planning process development that enables adding alternative outcomes generated from different environmental quality analysis processes to be assimilated into the masterplan (architecture/planning) program plans. Figure 10 demonstrates an alternative option for creating a unified planning process through which the outcomes (vector parameters, quantitative data, numerical codes, and more) of the different environmental quality analysis can be integrated into the planning program plans. For example: (1) spatial coding map for mapping layers of diverse environmental aspects; (2) numerical coding map for a program plan; and (3) table codes, which quantitatively describe each numeric outcome of the different qualities.

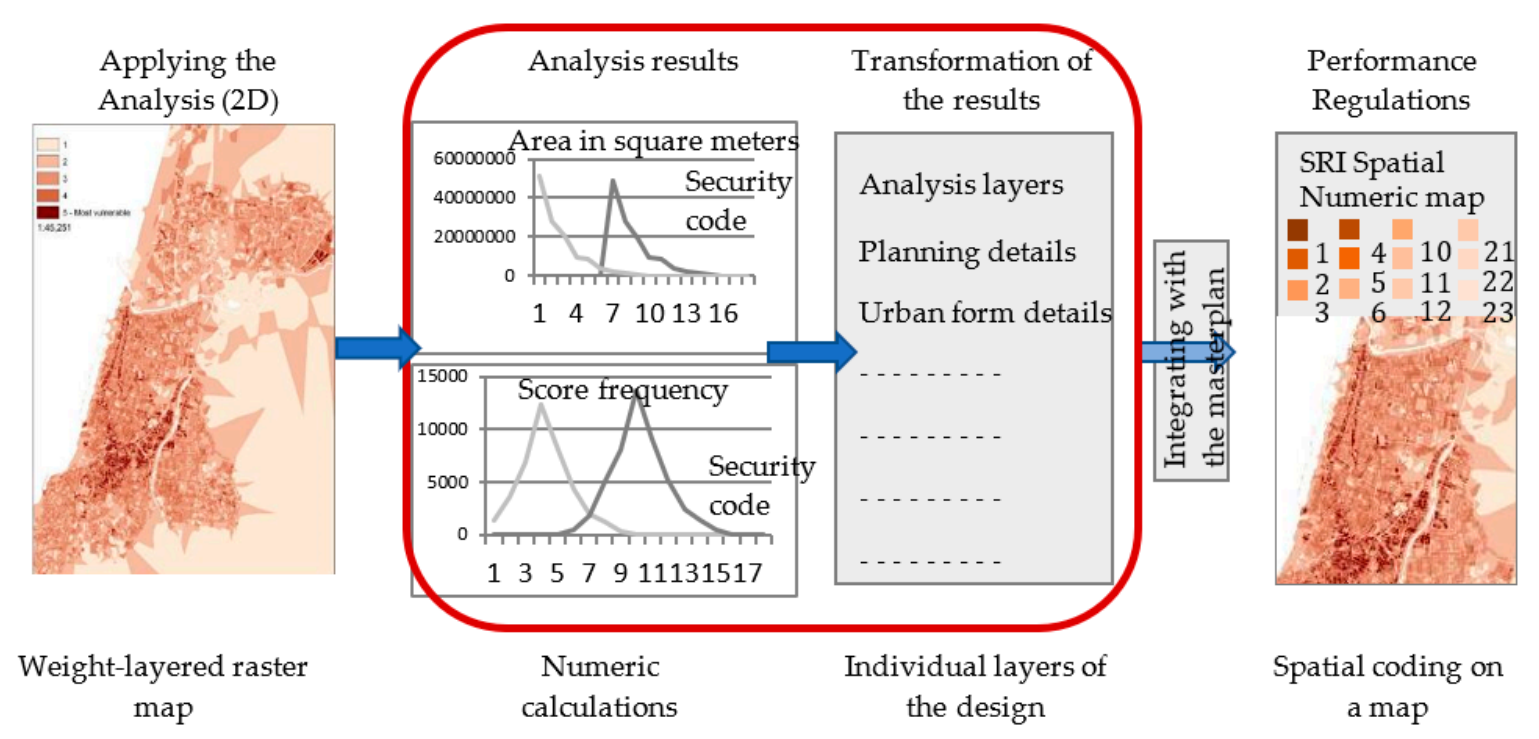

Figure 8. Demonstrating an alternative for the SRI security regulation code transformation into one layer of the design as an appendix to the masterplan program plans. 


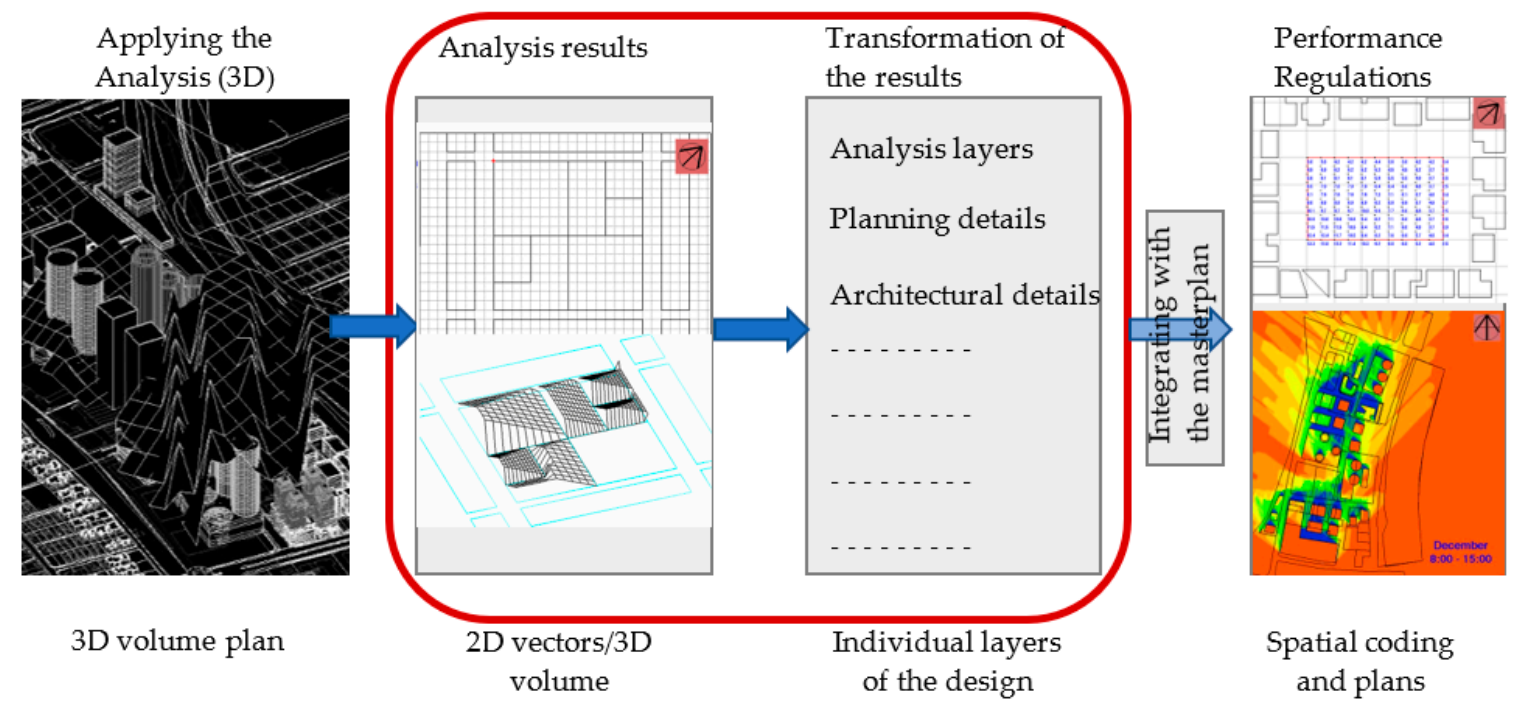

Figure 9. Demonstrating an alternative for the SRE solar rights envelope code transformation into one layer of the design as an appendix to the masterplan program plans.

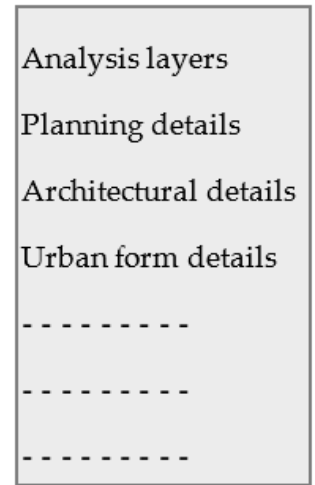

Individual layers of the design

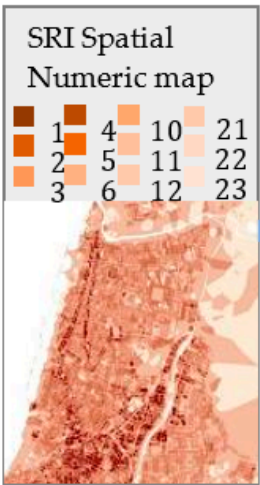

Spatial coding on a map

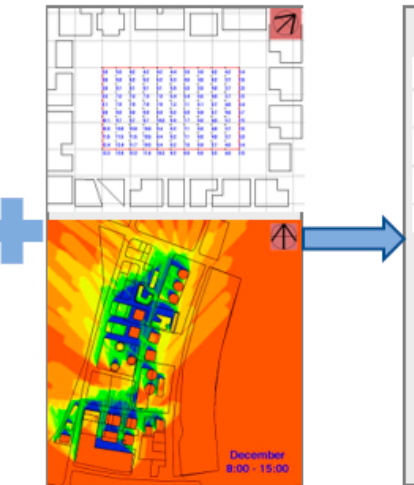

Spatial coding and plans

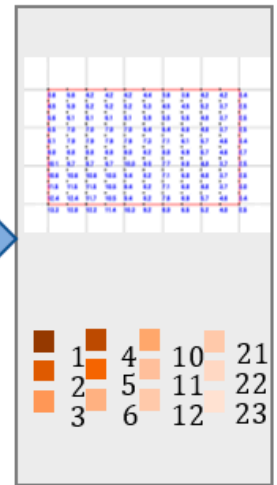

Code appendix

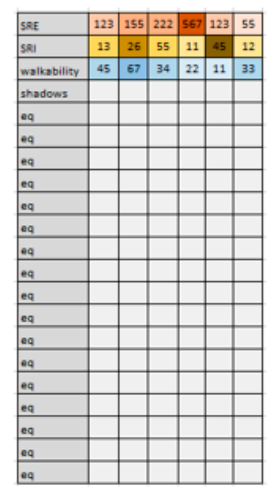

Coding table

Figure 10. Demonstrating a comprehensive performance evaluation alternative of different environment qualities, and assimilating the outcomes into the planning process, integrating both architectural and planning perspectives.

\section{Conclusions}

This paper introduces a novel approach for integrating performance parameters that affect the quality of life, early into the planning and design process. However, the main concern refers to the question of which form and urban language of performance aspect can or should be integrated into the planning and design process, and at what stage of the planning process performance should be integrated. Figures 8 and 9 show two alternatives for integrating performance-evaluation layers which present evaluation based on form (SRI) and generation layers which present form that embeds performance (SRE). Both alternatives suggest exposing aspects of performance through drawing plans or code tables as part of the planning/design process. Advanced future research needs to be developed to transform the performance results to the planning/design language as well as drive to include them in planning regulations. Figure 10 visually demonstrates these alternatives and shows a preliminary performance language to be integrated into the planning/design process.

There are diverse qualitative aspects that will be challenging to analyze and which are transformed into performance results and expressed by the planning/design language such as: clean and tidy, unpolluted, secure, safe, socially inclusive and fulfilling, economically vital and viable, and physically 
attractive; however, they could be highly determinant of the urban performance, due to their cultural, social or symbolic significance. Therefore, additional research needs to be done of developing models and tools for analyzing these qualitative measurements and transforming their results into either a code appendix, spatial coding on a map, or into a code table. Furthermore, additional performance evaluation alternatives need to be developed to exhibit different types and parameters of qualitative aspects.

As mentioned already, an important factor in the development of FBC is public participation, allowing the proposals to be highly visible and accessible, where all stakeholders can collaborate as part of the planning process. The proposed PBC method must consider the participation of the local community in the selection of the topics of concern and the elaboration of the performance requirement, encouraging a bottom-up approach for the generation of the urban form. The ability to generate a quality evaluation of the designed plans during the planning and design process is significant.

This approach proposed in this paper may produce conflicts between opposing demands and, at times, may lead to contradictions. It is clear that introducing more environmental aspects can lead to conflicts and therefore, negotiations, as well as increase the complexity of the route to find a solution. This may require a subjective decision by the designer regarding priorities and/or the employment of other external fitness criteria to be able to find an acceptable solution. Moreover, having a solution space implies that there is no one best optimal solution, allowing design freedom. The lack of a single solution suggests that we ought to think of a generation process that produces alternatives to be evaluated at a second stage rather than developing a single design in the traditional way [80]. To conclude, by adding performance layers to the planning and design process, planning regulations can include performance requirements as part of the planning demands, while ensuring environmental qualities.

Author Contributions: All authors contributed equally to the compilation of this article and to the preparation of the final manuscript. Conceptualization, D.S.-P. and I.G.C.; Formal analysis, D.S.-P. and I.G.C.; Investigation, D.S.-P. and I.G.C.; Methodology, D.S.-P. and I.G.C.; Visualization, D.S.-P. and I.G.C.; Writing —original draft, D.S.-P. and I.G.C.; Writing-review \& editing, D.S.-P. and I.G.C. All authors have read and agreed to the published version of the manuscript.

Funding: This research received no external funding.

Conflicts of Interest: The authors declare no conflict of interest.

\section{References}

1. Capeluto, I.G. The influence of the urban environment on the availability of the daylighting in office buildings in Israel. Build. Environ. 2003, 38, 745-752. [CrossRef]

2. Van den Dobbelsteen, A.; Thijssen, S.; Colaleo, V.; Metz, T. Ecology of the Building Geometry—Environmental Performance of Different Building Shapes. In Proceedings of the CIB World Building Congress, Cape Town, South Africa, 14-17 May 2007.

3. Shach-Pinsly, D. Measuring Security in the Built Environment: Evaluating Urban Vulnerability in a Human-Scale Urban Form. Landscape Urban Plan 2019, 191. [CrossRef]

4. Cerin, E.; Saelens, B.E.; Sallis, J.F.; Frank, L.D. Neighborhood Environment Walkability Scale: Validity and development of a short form. Med. Sci. Sports Exerc. 2006, 38, 1682-1691. [CrossRef] [PubMed]

5. Shach-Pinsly, D. Visual exposure and visual openness analysis model used as evaluation tool during the urban design development process. J. Urban. 2010, 3, 161-184. [CrossRef]

6. Capeluto, I.G. Design Tools for Asking Questions: Evaluation vs. Generation. EAAE Trans. Archit. Educ. 2013, 61, 602-613.

7. Mackey, C.; Sadeghipour Roudsari, M. The Tool(s) vs. The Toolkit. In Proceedings of the Design Modeling Symposium, Paris, France, 18-20 August 2017.

8. Carmona, M.; Sieh, L. Measuring Quality in Planning: Managing the Performance Process; Routledge: Abingdon, UK, 2004.

9. Baker, D.C.; Sipe, N.G.; Gleeson, B.J. Performance-based planning: Perspectives from the United States, Australia, and New Zealand. J. Plan. Educ. Res. 2006, 25, 396-409. [CrossRef]

10. Fredland, D.R. Environmental Performance Zoning: An Emerging Trend? Urban Lawyer 1980, 12, 678-699. 
11. Romice, O.; Thwaites, K.; Porta, S.; Greaves, M.; Barbour, G.; Pasino, P. Urban design and quality of life. In Handbook of Environmental Psychology and Quality of Life Research; Springer: Cham, Switzerland, 2017; pp. 241-273.

12. Carmona, M. The place-shaping continuum: A theory of urban design process. J. Urban Des. 2014, 19, 2-36. [CrossRef]

13. Alfasi, N.; Portugali, J. Planning rules for a self-planned city. Plan. Theory 2007, 6, 164-182. [CrossRef]

14. Healey, P. Planning through debate: The communicative turn in planning theory. Town Plan. Rev. 1992, 63, 143. [CrossRef]

15. Inniss, L.B. Back to the future: Is form-based code an efficacious tool for shaping modern civic life? J. Low Chang. 2007, 11, 75.

16. Carmona, M. Place value: Place quality and its impact on health, social, economic and environmental outcomes. J. Urban Des. 2019, 24, 1-48. [CrossRef]

17. Waldner, L.S. Planning to perform: Evaluation models for city planners. Berkeley Plan. J. 2004, 17. [CrossRef]

18. Carmona, M.; Magalhães, C.D. Local Environmental Quality- A New View on Measurement; Communities and Local Government Publications: London, UK, 2007.

19. Baer, W.C. General plan evaluation criteria: An approach to making better plans. J. Am. Plan. Assoc. 1997, 63, 329-344. [CrossRef]

20. Kent, T.J. The Urban General Plan, 2nd ed.; The American Planning Association: Chicago, IL, USA, 1990; Available online: https://www.amazon.com/Urban-General-Plan-Jr-Kent/dp/0918286735 (accessed on 13 July 2020).

21. Oliveira, V.; Pinho, P. Evaluation in Urban Planning: Advances and Prospects. J. Plan. Lit. 2010, $24,343-361$. [CrossRef]

22. Talen, E. After the Plans: Methods to Evaluate the Implementation Success of Plans. J. Plan. Educ. Res. 1996, 16, 79-91. [CrossRef]

23. Sharifi, A.; Murayama, A. A critical review of seven selected neighborhood sustainability assessment tools. Environ. Impact Assess. Rev. 2013, 38, 73-87. [CrossRef]

24. Gauthier, M. Urban planning and sustainable development. Introductory note. Environ. Urbain/Urban Environ. 2009, 3, 5.

25. González, A.; Donnelly, A.; Jones, M.; Chrysoulakis, N.; Lopes, M. A decision-support system for sustainable urban metabolism in Europe. Environ. Impact Assess. Rev. 2013, 38, 109-119. [CrossRef]

26. Yigitcanlar, T.; Teriman, S. Rethinking sustainable urban development: Towards an integrated planning and development process. Int. J. Environ. Sci. Technol. 2015, 12, 341-352. [CrossRef]

27. Orenstein, D.E.; Shach-Pinsley, D. A comparative framework for assessing sustainability initiatives at the regional scale. World Dev. 2017, 98, 245-256. [CrossRef]

28. Yigitcanlar, T.; Dur, F. Developing a sustainability assessment model: The sustainable infrastructure, land-use, environment and transport model. Sustainability 2010, 2, 321-340. [CrossRef]

29. Ameen, R.F.M.; Mourshed, M.; Li, H. A critical review of environmental assessment tools for sustainable urban design. Environ. Impact Assess. Rev. 2015, 55, 110-125. [CrossRef]

30. Kramar, U.; Dragan, D.; Topolšek, D. The Holistic Approach to Urban Mobility Planning with a Modified Focus Group, SWOT, and Fuzzy Analytical Hierarchical Process. Sustainability 2019, 11, 6599. [CrossRef]

31. Sumari, N.S.; Xu, G.; Ujoh, F.; Korah, P.I.; Ebohon, O.J.; Lyimo, N.N. A Geospatial Approach to Sustainable Urban Planning: Lessons for Morogoro Municipal Council, Tanzania. Sustainability 2019, 11, 6508. [CrossRef]

32. Wei, Y.; Huang, C.; Lam, P.T.; Yuan, Z. Sustainable urban development: A review on urban carrying capacity assessment. Habitat Int. 2015, 46, 64-71. [CrossRef]

33. Demirtas, O. Evaluating the best renewable energy technology for sustainable energy planning. Int. J. Energy Econ. Policy 2013, 3, 23-33.

34. Wu, S.R.; Fan, P.; Chen, J. Incorporating culture into sustainable development: A cultural sustainability index framework for green buildings. Sustain. Dev. 2016, 24, 64-76. [CrossRef]

35. U.S. Green Building Council. Leadership in Energy and Environmental Design (LEED). 2001. Available online: https://www.usgbc.org/leed (accessed on 29 March 2020).

36. Roderick, Y.; McEwan, D.; Wheatley, C.; Alonso, C. Comparison of energy performance assessment between LEED, BREEAM and Green Star. In Proceedings of the Eleventh International IBPSA Conference, Glasgow, Scotland, 27-30 July 2009. 
37. Szibbo, N.A. Livability and LEED-ND: The Challenges and Successes of Sustainable Neighborhood Rating Systems. Ph.D. Thesis, UC Berkeley, Berkeley, CA, USA, 2015.

38. Wheeler, S.M. Green Architecture and Building, Planning for Sustainability: Creating Livable, Equitable and Ecological Communities, 2nd ed.; Routledge: Abingdon, UK, 2013; pp. 194-196.

39. Lee, W.L.; Burnett, J. Benchmarking energy use assessment of HK-BEAM, BREEAM and LEED. Build. Environ. 2008, 43, 1882-1891. [CrossRef]

40. The Standards Institution of Israel. Israel Standard SI 5281, version 1; Buildings with Reduced Environmental Impact (Green Buildings): Tel Aviv, Israel, 2005.

41. The Standards Institution of Israel. Israel Standard SI 5281, version 2; Sustainable Building (Green Building): Tel Aviv, Israel, 2011.

42. Capeluto, I.G.; Ben-Avraham, O. Assessing the green potential of existing buildings towards smart cities and districts. Indoor Built Environ. 2016, 25, 1124-1135. [CrossRef]

43. Neighborhood 360. The Israeli Green Building Council (ILGBC). 2019. Available online: http://www.nd360. org/ (accessed on 5 December 2019).

44. Index, C.R. City Resilience Framework; The Rockefeller Foundation and ARUP: New York, NY, USA, 2014.

45. Fitzgibbons, J.; Mitchell, C. Just urban futures? Exploring equity in "100 Resilient Cities". World Dev. 2019, 122, 648-659. [CrossRef]

46. Pfefferbaum, R.L.; Pfefferbaum, B.; Van Horn, R.L.; Klomp, R.W.; Norris, F.H.; Reissman, D.B. The communities advancing resilience toolkit (CART): An intervention to build community resilience to disasters. J. Public Health Manag. Pract. 2013, 19, 250-258. [CrossRef] [PubMed]

47. Babcock, R.F. The Zoning Game' Municipal Practices and Policies; The University of Wisconsin Press: Madison, WI, USA, 1966; p. 202.

48. Mehaffy, M.W. Generative methods in urban design: A progress assessment. J. Urban. 2008, 1, 57-75. [CrossRef]

49. Mueller, J.; Lu, H.; Chirkin, A.; Klein, B.; Schmitt, G. Citizen Design Science: A strategy for crowd-creative urban design. Cities 2018, 72, 181-188. [CrossRef]

50. Gil, J.; Pinto Duarte, J. Towards an urban design evaluation framework. In Proceedings of the Architecture in Computro 26th eCAADe Conference Proceedings, Antwerpen, Belgium, 17-20 September 2008.

51. Karimi, K. A configurational approach to analytical urban design:'Space syntax'methodology. Urban Des. Int. 2012, 17, 297-318. [CrossRef]

52. Ochoa, C.E.; Capeluto, I.G. Advice tool for early design stages of intelligent facades based on energy and visual comfort approach. Energy Build. 2009, 41, 480-488. [CrossRef]

53. Mela, K.; Tiainen, T.; Heinisuo, M. Comparative study of multiple criteria decision making methods for building design. Adv. Eng. Inform. 2012, 26, 716-726. [CrossRef]

54. Evins, R. A review of computational optimisation methods applied to sustainable building design. Renew. Sustain. Energy Rev. 2013, 22, 230-245. [CrossRef]

55. Liu, S.; Meng, X.; Tam, C. Building information modeling based building design optimization for sustainability. Energy Build. 2015, 105, 139-153. [CrossRef]

56. Space, C.A.B.E. Spaceshaper: A User's Guide; CABE: London, UK, 2007.

57. Mehta, V. Evaluating Public Space. J. Urban Des. 2014, 19, 53-88. [CrossRef]

58. Delsante, I. Urban environment quality assessment using a methodology and set of indicators for medium-density neighbourhoods: A comparative case study of Lodi and Genoa. Ambiente Construído 2016, 16, 7-22. [CrossRef]

59. Marwedel, J. Opting for performance: An alternative to conventional zoning for land use regulation. J. Plan. Lit. 1998, 13, 220-231. [CrossRef]

60. Parolek, D.G.; Parolek, K.; Crawford, P.C. Form Based Codes: A Guide for Planners, Urban Designers, Municipalities, and Developers; John Wiley \& Sons: Hoboken, NJ, USA, 2008.

61. Rangwala, B.K. Form-based codes. Econ. Dev. J. 2012, 11, 35-41.

62. Talen, E. Design by the rules: The historical underpinnings of form-based codes. J. Am. Plan. Assoc. 2009, 75, 144-160. [CrossRef]

63. Ewing, R.; Handy, S. Measuring the unmeasurable: Urban design qualities related to walkability. J. Urban Des. 2009, 14, 65-84. [CrossRef]

64. Gehl, J. Cities for People; Island Press: Washington, DC, USA, 2010. 
65. Ewing, R.; Clemente, O. Measuring Urban Design: Metrics for Livable Places; Island Press: Washington, DC, USA, 2013.

66. Forsyth, A.; Oakes, J.M. Cycling, the built environment, and health: Results of a midwestern study. Int. J. Sustain. Transp. 2015, 9, 49-58. [CrossRef]

67. Giles-Corti, B.; Vernez-Moudon, A.; Reis, R.; Turrell, G.; Dannenberg, A.L.; Badland, H.; Owen, N. City planning and population health: A global challenge. Lancet 2016, 388, 2912-2924. [CrossRef]

68. Kalay, E.Y. Performance-based design. Autom. Constr. 1999, 8, 395-409. [CrossRef]

69. Grobman, Y.J.; Yezioro, A.; Capeluto, I.G. Computer-based Form Generation in Architectural Design-A Critical Review. Int. J. Archit. Comput. 2009, 7, 535-554. [CrossRef]

70. Capeluto, I.G. Dense cities in temperate climates: Solar and daylight rights. In Solar Energy at Urban Scale; Beckers, B., Ed.; ISTE Ltd: London, UK; John Wiley \& Sons, Inc.: Hoboken, NJ, USA, 2012. [CrossRef]

71. Shaviv, E. A method for the design of fixed external sunshades. In Build International; Applied Science Publishers: Brighton, UK, 1975; Volume 8, pp. 121-150.

72. Shaviv, E. Design Tools for Solar Rights and Sun-shades Determination. In Proceedings of the Ninth National Passive Solar Conference, ASES, Boulder, CO, USA, 23 September 1984; pp. 14-19.

73. Arumi, F. Computer-Aided Energy Design for Buildings. In Energy Conservation Through Building Design; Watson, D., Ed.; McGraw-Hill: New York, NY, USA, 1979; pp. 141-160.

74. Knowles, R.L. Sun Rhythm Form; MIT Press: Cambridge, MA, USA, 1981.

75. Knowles, R.L.; Villecco, M.N. Solar Access and Urban Form. AIA J. 1980, 70, $42-49$.

76. Capeluto, I.G.; Shaviv, E. On the Use of Solar Volume for Determining the Urban Fabric. Sol. Energy J. 2001, 70, 275-280. [CrossRef]

77. Capeluto, I.G.; Plotnikov, B. A method for the generation of Climate-based, context dependent Parametric Solar Envelopes. Archit. Sci. Rev. 2017, 60, 395-407. [CrossRef]

78. Capeluto, I.G.; Yezioro, A.; Shaviv, E. Climatic Aspects in Urban Design - A Case Study. Build. Environ. 2003, 38, 827-835. [CrossRef]

79. MVRDV. Bastide-Niel Master Project. 2010. Available online: https://www.mvrdv.nl/projects/zac-bastide-niel (accessed on 5 December 2019).

80. Grobman, Y.J.; Yezioro, A.; Capeluto, I.G. Non-Linear Architectural Design Process. Int. J. Archit. Comput. 2010, 8, 41-54. [CrossRef] 